\title{
Advanced Anaerobic Digestion and Associated Process for Zero Discharge Biowastes Treatment
}

\author{
V B Manilal*, B Chitrajit, R S Dipin Nath
}

Environmental Technology, CSIR-National Institute for Interdisciplinary Science and Technology, Thiruvananthapuram 695019, India manilalvb@gmail.com

Abstract-Anaerobic digestion is an attractive option for the treatment of organic wastes because of the net energy gain from the process to offset part of the operational cost. Invariably management of discharges from the anaerobic digester requires further processing and most of the known methods are either expensive or complex to practice. A complete solution to the problem of biowastes treatment is discussed in this paper through an improved anaerobic digestion process where no additional water is to be used in the operation, and the conversion of the digestate to solid manure. The tubular anaerobic digester employed in the study could remove nearly $90 \%$ of the volatile solids and produce biogas of around 550 litres $/ \mathrm{kg}$ VS loading. The management of digester discharge was studied by following a method of evapouration drying by mixing with pre-dried discharged digester slurry to maintain combined moisture level below $60 \%$. The average evapouration rate of moisture by this method was 211.6 $\pm 16.6 \mathrm{~g} / \mathrm{kg} T \mathrm{~S} /$ day under ambient conditions.

Keywords- Anaerobic digestion, biowastes treatment, solid manure, tubular digester, evapouration, zero discharge.

\section{INTRODUCTION}

Anaerobic decomposition has been considered as a suitable method of wastes stabilization where generation of biogas is a valuable by-product. Currently it is applied widely not only to treat and dispose biowastes but for generating biogas fuel in bioenergy farms also (Wellinger, et al., 2013; Mao, et al., 2015; Scarlat, et al., 2018).

Generally the anaerobic digesters for bio-wastes and cattle manure treatment are operated by adding excess water to meet the design parameters (Mir, et al., 2016). This is done either by mixing freshwater or wastewater during grinding or smashing, and constituting to dilute slurries. Such preparations of slurry for the anaerobic digestion have certain immediate advantages because it could be handled like a liquid. Therefore such approaches demand the process design, treatment system design and operations similar to that in the anaerobic treatment of waste water. However, such cases of changing biowastes to dilute slurry prior to anaerobic treatment have serious disadvantages such as wasting of fresh water, converting of freshwater or less polluted water to high BOD wastewater, requirement to handle larger volume and thereby increases the digester volume, and the difficulty to manage increased volume of discharge.
There were some attempts to increase the solids content in the anaerobic digestion process by recycling the effluents and waste water (Smis, et al., 1995). The requirement of special facilities and their multi-step operations are turned out as major hurdles in such anaerobic digestion methods, especially when they are applied for smaller plants. Alternatively, dry anaerobic digestion of food wastes and other biowastes without water addition has also been reported where the process was affected due to the accumulation volatile fatty acids (Jansson, et al., 2019). Generally the microbial activity is expected to be affected seriously in the absence of minimal water medium because of the limitations for the microbes to access the substrates and nutrients in the system.

Most importantly in almost all anaerobic plants management of discharges from the process is a major problem that requires suitable methods of treatment to control further pollution (Møller, et al., 2009). Unless a suitable solution is developed the sustainability of anaerobic digestion becomes difficult despite of its merits including the production of biofuel during biowastes decomposition and treatment.

The present study is attempted to develop a complete solution to the problem of biowastes treatment through an improved anaerobic digestion process and augmented 
evapouration drying of the digested discharge without energy intensive operations.

\section{MATERIALS AND METHODS}

\subsection{Advanced Anaerobic Tubular Digester}

An anaerobic double tubular digester (ADTD) was designed based on the principle of plug flow slurry digestion developed previously for household biowastes treatment (Manilal, 2012).

\subsubsection{ADTD Set up}

The ADTD was fabricated in mild steel plate of $3 \mathrm{~mm}$ thickness and each tube had $1000 \mathrm{~mm}$ internal diameter and $2500 \mathrm{~mm}$ length. A centrally fixed shaft with spokes provided in each tubular digester was used to mix the content periodically with a geared motor assembly. Both the digesters were mounted on separate stands in parallel and had the ground clearance of $400 \mathrm{~mm}$. At the end of one tube a feed port was fixed at the top for loading the biowastes. A connecting pipe of $200 \mathrm{~mm}$ diameter was fitted at the opposite side of the feed port to overflow the liquid from the first tube to the second tube as on feeding and filling the first tube. A schematic of the digester is shown in Fig. 1. Rusting of the tubular digester was prevented by coating epoxy paint outside and rubberised coating inside.

Biogas from the anaerobic digestion was collected in a $3 \mathrm{~m}^{3}$ biogas balloon placed on a steel stand. Installation of the ADTD was done in the laboratory and leak was tested by filling water prior to the introduction of seeding material and commissioning of the plant.

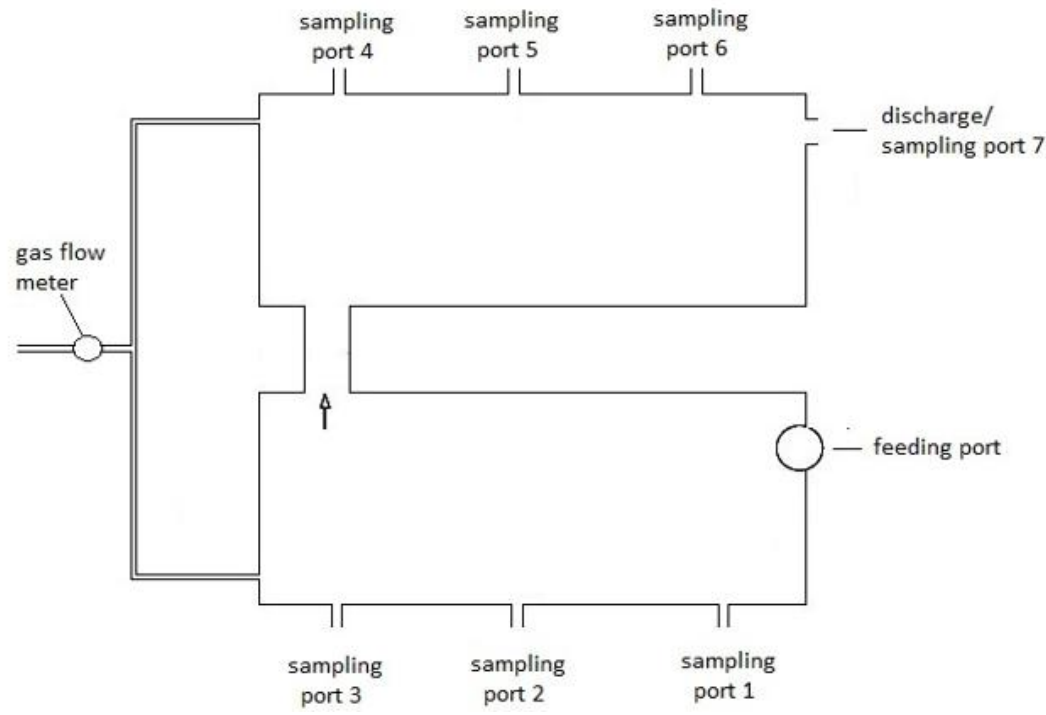

Fig. 1: Schematic diagram of anaerobic double tubular digester (ADTD)

\subsubsection{Seeding Material and Biowastes}

Initial seed for the ADTD was constituted by mixing anaerobic sludge from the laboratory biogas plant and cow dung slurry by adding water in the ratio $1: 1$. Total solids content of the seed was around $4.6 \%$.

Biowastes of the CSIR-NIIST canteen containing food wastes and the vegetable wastes of food preparation was the feed to the digester, which was collected, weighed and fed to the digester after grinding in a hammer mill every day except on Saturdays and Sundays. The ADTD was operated initially by feeding $5 \mathrm{~kg}$ biowastes on weekly basis for two weeks and changed to alternate days thereafter. The biowastes feeding of $5 \mathrm{~kg}$ was continued on daily basis from fourth week and the feeding rate was then increased to $10 \mathrm{~kg} /$ day from second month. Biowastes feeding was stepped up gradually by monitoring the volatile fatty acids in the ADTD and reached to the maximum of $50 \mathrm{~kg}$ /day from fourth month. At the experimental period the organic loading rate (OLR) of the reactor was $1.97 \pm 0.6 \mathrm{kgVS} / \mathrm{m}^{3} /$ day and $2.78 \pm 0.9 \mathrm{~kg} \mathrm{COD} / \mathrm{m}^{3} /$ day, at a hydraulic retention time (HRT) of 150 days. The digester was operated at ambient average temperature of $33^{\circ} \mathrm{C}$.

2.1.3. Analysis of Biowastes

Samples were collected from all ports on a regular basis and measured the temperature and $\mathrm{pH}$ using a systronic $\mathrm{pH}$ system 362, and VFA and alkalinity were estimated by following the method of Anderson and Yang (1992). Analyses were also done for COD, total solids, total 
dissolved solids and total suspended solids as per the standard methods (APHA 1988). The COD and VS removal efficiency was derived using the formula described by Mohan and Bindu (2008). Average results of the duplicates/triplicates were accounted for each parameter on wet weight basis of the biowastes.

\subsection{Slurry Drying}

\subsubsection{Preparation of Absorbent}

The discharged digestate slurry from the ADTD was dried in sun light by spreading thinly in a metallic tray. During drying sticking and hardening of the material was prevented through periodical mixing prior to drying completely. The dried material prepared from the slurry was further shredded to breakdown the aggregates and used as the absorbent which had around $25 \%$ moisture.

\subsubsection{Drying Bed}

An absorbent bed of $50 \mathrm{~mm}$ thickness was prepared from the dried digestate. During drying fresh digestate of the ADTD was mixed with the absorbent bed in the ratio of 4:1 roughly so as to have maximum moisture not more than $60 \%$ in the mixture. The mixture was kept for evapouration drying under a roofed platform at the ambient temperature of around $33^{\circ} \mathrm{C}$. The moisture content was measured every day before and after fresh addition of digestate. Using the absorbent bed the evaporation drying was repeated for 17 days and the data was collected.

\section{RESULTS AND DISCUSSION}

Two important tasks were involved in this study of treating biowastes and recovery of by-products without environmental pollution; the first effort was designing and testing of a suitable anaerobic digester to function free of added moisture, and the second part was the energy free removal of moisture from the anaerobic digestate (treated slurry of the anaerobic digester) to produce solid manure. The experimental ADTD was fed with the ground biowastes without adding extra water and operated at the moisture content available in the biowastes.

\subsection{Feed Character}

The total solids (TS) of the biowastes were varied from 172 to $235 \mathrm{~g} / \mathrm{kg}$ wet weight with an average of $202 \mathrm{~g} / \mathrm{kg}$ and the volatile solids (VS) were in the range of 152 to $216 \mathrm{~g} / \mathrm{kg}$ and an average of $181 \mathrm{~g} / \mathrm{kg}$ of wet sample. The chemical oxygen demand (COD) of the waste samples was ranged from 220 to $337 \mathrm{~g} / \mathrm{kg}$ having an average value of $255 \mathrm{~g} \mathrm{COD} / \mathrm{kg}$ wet sample. The biowastes had the carbon nitrogen ratio of around 17. The analyses results of TS, VS and COD of the biowastes fed to the ADTD are presented in the Fig. 2.

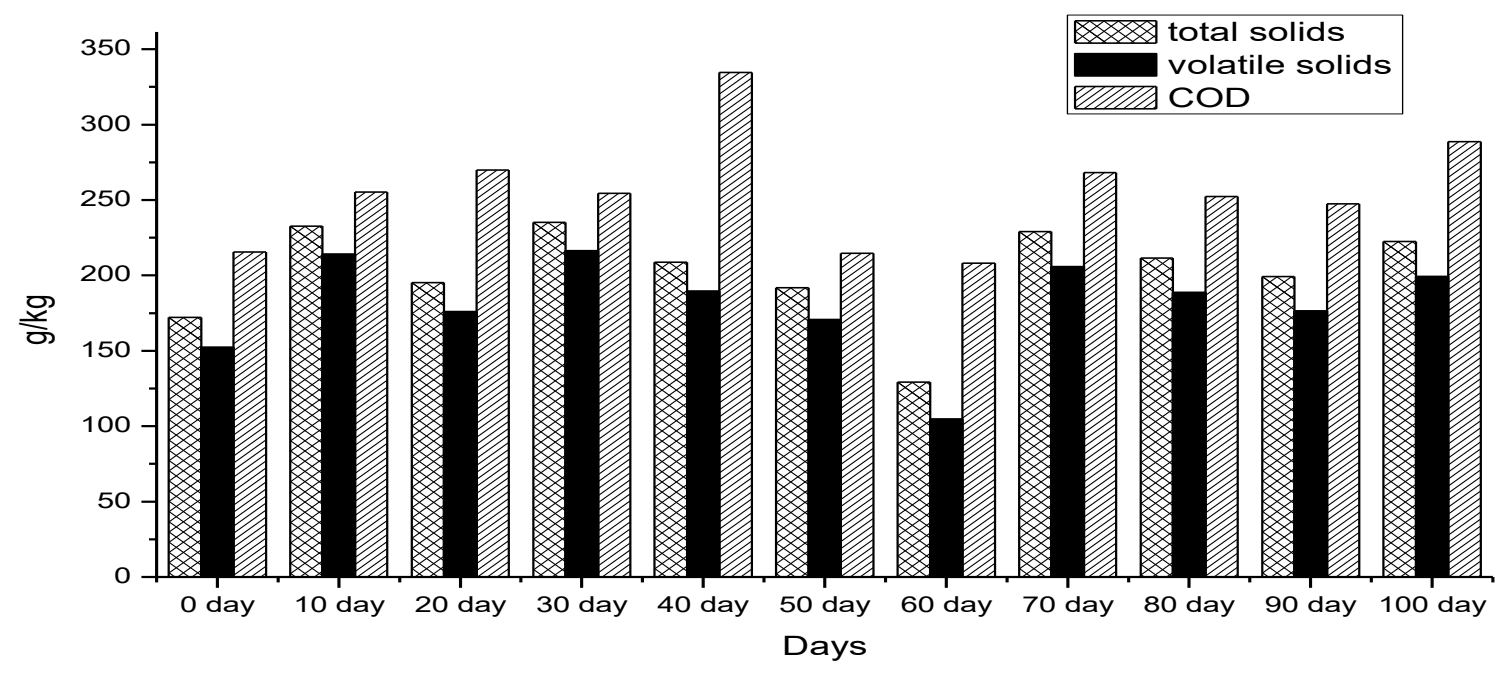

Fig. 2: Total solids, volatile solid and COD of the biowastes feed administered to the ADTD

\subsection{Biogas production}

The online reading of biogas production recorded every day by using a wet gas flow meter is presented in Fig. 3. The pattern of daily biogas production was more or less similar except on unfed days in the weekends. Biogas generation was almost instantaneous on feeding and an average production was more than 100 liters per kilogram of fresh biowastes. The average biogas production was nearly 
550litres / kg VS loading which was higher than the earlier reports with the anaerobic digestion of similar biowastes
(Zhang, et al.,2007; Ragazzia, et al., 2017).

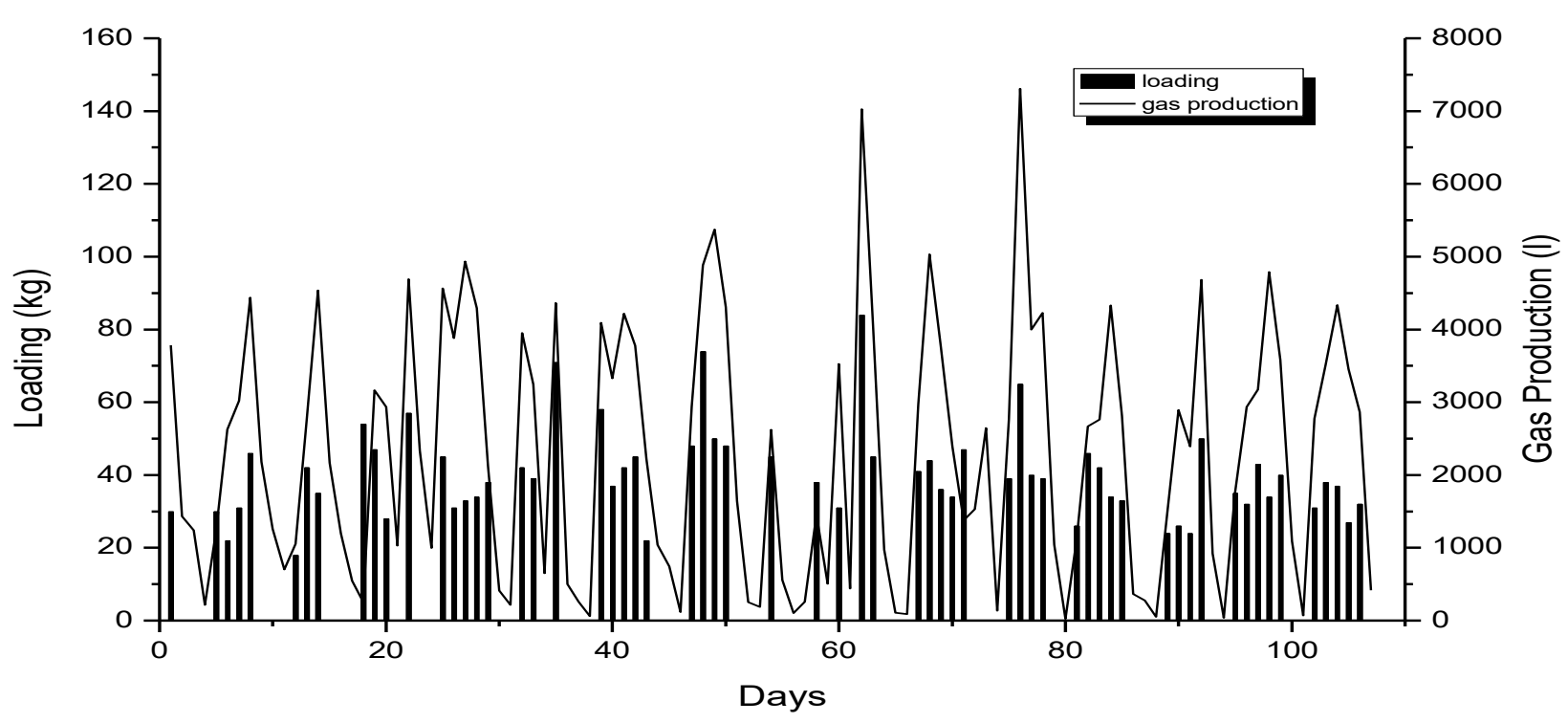

\subsection{Performance of the ADTD}

Fig. 3: Biowastes loading and biogas generation in the ADTD

The anaerobic digestion of the wastes was assessed by analyzing samples collected from 1 to 6 sample ports and from the final digestate discharge port 7 of the ADTD. The $\mathrm{pH}$ at the port 1 of ADTD was maintained above 6.8 automatically and therefore no additional buffering was required for the smooth operation of digester. While passing through every section of ADTD there was an increase of the $\mathrm{pH}$ further as evidenced by the analysis of samples drawn from $2^{\text {nd }}$ port and beyond, and it was around 8.0 in the final discharge (Fig. 4a). This is an indication of stable anaerobic

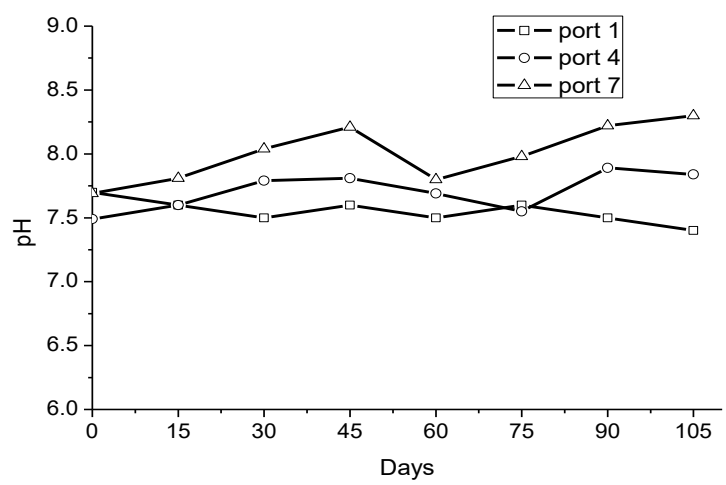

Fig.4a: pH measurements in different sample ports of ADTD during operation digestion ideally suitable for the biodegradation process (Buswell, et al.,1952, Liu, et al., 2008, Anthony, et al., 2019). The results of VFA analysis show variations at different sections of the ADTD as the anaerobic degradation and movement of the wastes proceeded from the feeding point to the discharge port (Fig. 4b). The material heterogeneity in the biowastes is expected to result varied pattern of biodegradation in the system and such patterns have been reported in the earlier studies on anaerobic digestion (Mohanan and Bindu, 2008).

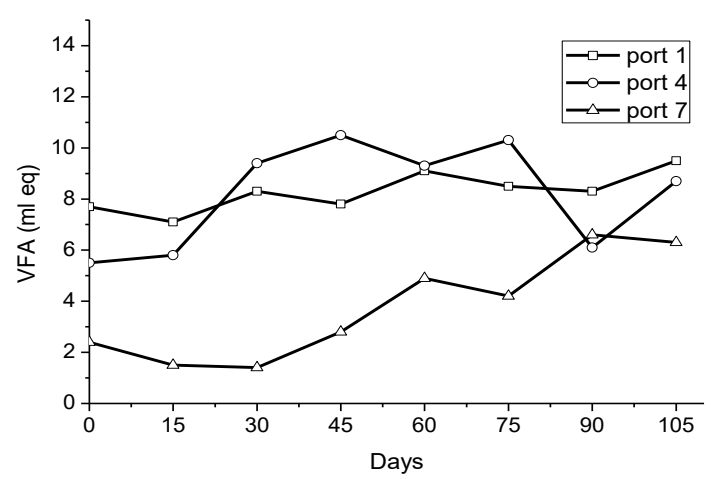

Fig.4b: VFA recorded in different sample ports of ADTD during operation 


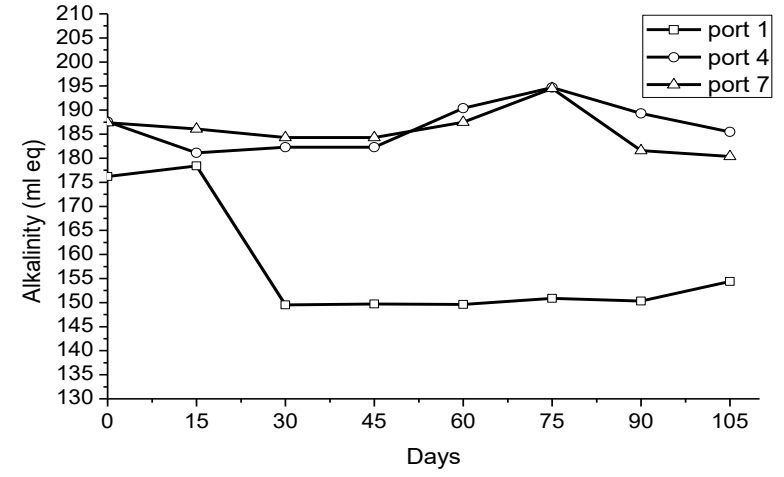

Fig.4c: Alkalinity readings in different sample ports of ADTD during the treatment period

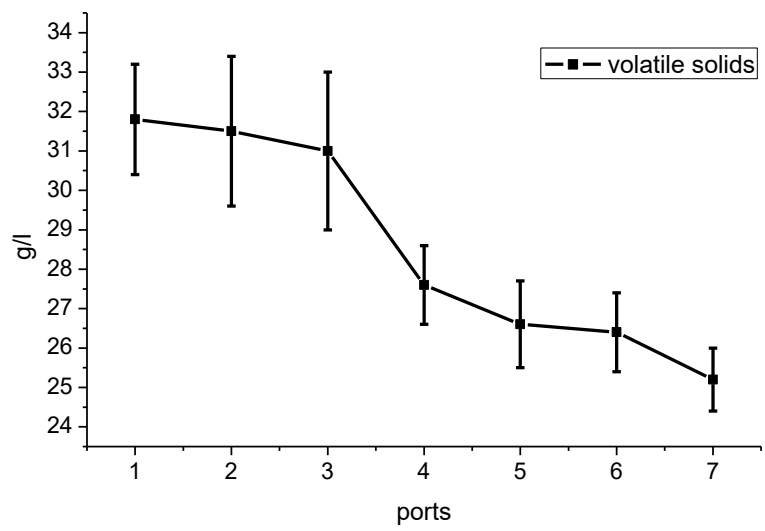

Fig. 4e: VS contents in different sample ports of ADTD during the treatment period

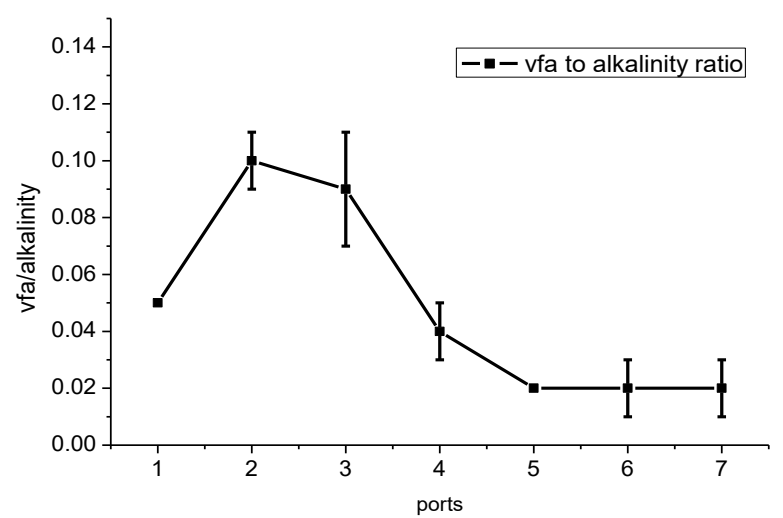

Fig.4d: VFA to alkalinity ratio calculated from the values measured at different sample ports of ADTD during the treatment period

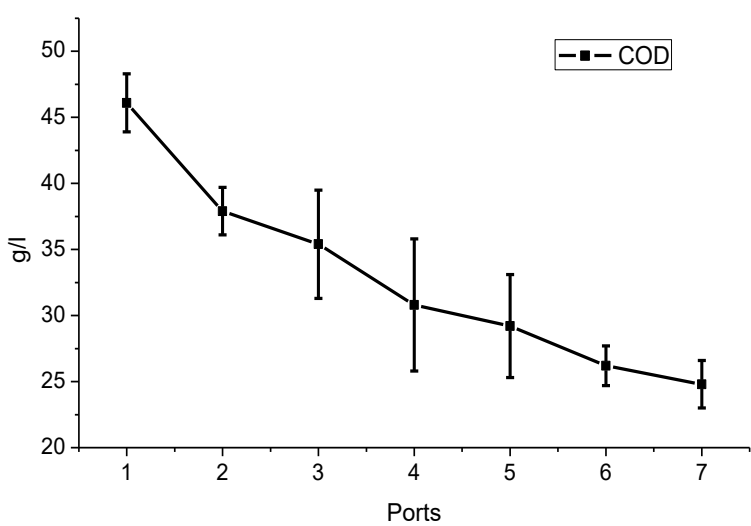

Fig. 4f: COD measurements in different sample ports of $A D T D$ during the treatment period

Fig. 4a-f: Results of sample analysis collected from different sections of the ADTD on feeding biowastes

The build up of alkalinity in ADTD was measured and presented in Fig. $4 c$ for assessing the stability of anaerobic function at different sections. The ratio between VFA and alkalinity is an indicator of the digester performance, which was found desirable below 0.4 (Callaghan et al., 2002), and in ADTD the values were maintained constantly within that range (Fig.4d).

The reduction of volatile solids was more than $85 \%$ by the anaerobic digestion of biowastes in ADTD. The results were consistent throughout the digestion period and the pattern of VS removal is presented in Fig. 4e, which indicates the stable performance of ADTD.

COD removal was significantly high in the ADTD, and it was accounted to about $90 \%$. The section wise results of COD removal obtained from sampling ports are presented in
Fig. $4 f$ and it shows the effective degradation and treatment of biowastes in the ADTD. Because of the effective treatment of the biowastes the digestate from the anaerobic digester had low COD and volatile solids. The stabilization of wastes by the process thus demonstrates the possible use of the digestate directly for soil application safely.

\subsection{Drying of digestate}

Conversion of slurry discharges from the anaerobic digester to solid manure is the most desirable value recovery process for the sustainable operation and pollution free management of the process. However, the direct air drying of the digester slurry is extremely slow and difficult because of the limited contact surface of moisture evapouration as it has been reported for sewage sludge (Flaga, 2005). Results of this 
study demonstrated the removal of moisture from the digestate at the rate of $211.6 \pm 16.6 \mathrm{~g} / \mathrm{kgTS} /$ day approximately (Fig. $5 a$ ). As a result solids were accumulated at a constant rate, which further enhanced the quantity of the absorption bed and the moisture absorption rate from the digestate to expedite the drying process (Fig. $5 b$ ).

Restricting the total moisture to less than $60 \%$ in every addition of fresh digestate was favourable for easy passage of air as it has been reported as optimum in aerobic composting of biological materials (Diaz, et al., 2002). The usual limitation of slurry drying with respect to mass transfer could be improved in this method by extending the contact surface of moisture evapouration.

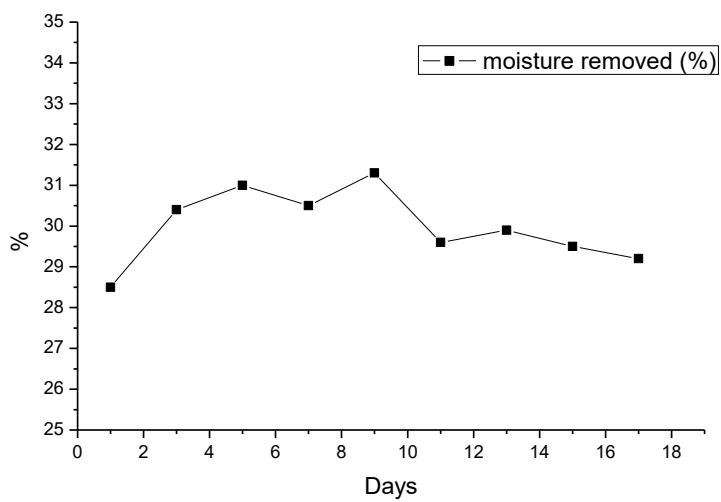

Fig. 5a: Moisture removed from the bed material during drying

Fig. 5a-b: Results of the evaporation drying with the extended contact surface using absorption bed.

\section{CONCLUSION}

Biowastes treatment in the advanced anaerobic digester was found effective in removing the volatile solids to $85 \%$, COD content to $90 \%$ and stable production of biogas to the tune of $550 \mathrm{litrs} / \mathrm{kg} / \mathrm{VS}$. The performance of anaerobic double tubular digester system was better than many other existing models for biowastes treatment particularly for reducing water use and discharge volume, and concentrating solids in the discharge. This method to obtain higher concentration of solids in the discharge could reduce the problems of digestate drying and management.

The drying of anaerobic digestate by mixing with pre-dried absorbent bed and extending contact surface of evapouration was found appropriate, and it could demonstrate the repeated absorption and evapouration of water from the material to generate solid manure. The rate of evapouration drying is controlled mainly by humidity and temperature of the site of
Atmospheric temperature and relative humidity are the governing factors that influence the rate of evapouration and drying at ambient conditions. However such limitations have little importance in this method as there is no costly energy input involved in the process.

This process of drying has several advantages which include; 1) solids are recovered from the digestate without energy intensive methods, 2) enables complete stabilization possible by aeration during the process, 3) produces organic manure without nutrients loss, 4) easy to handle the liquid discharge, 5) manure production from the treatment process, and thus the anaerobic treatment becomes more attractive.

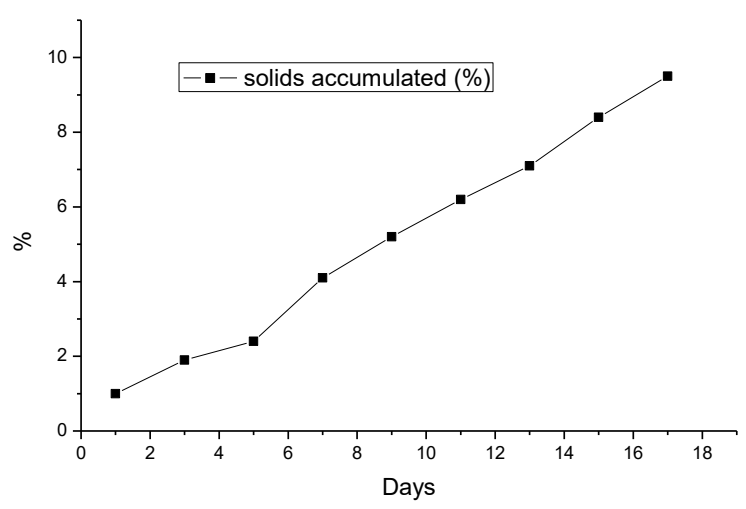

Fig. 5b: Solids accumulated in the bed during drying operation but has less significance on operation cost as the method could be applied without energy input.

\section{ACKNOWLEDGMENTS}

The authors thank CSIR, India for providing the necessary funding to carry out the work.

\section{REFERENCES}

[1] American Public Health Association, A.P.H.A., (1998). Standard methods for the examination of water and wastewater. 20th Edition, Washington D C

[2] Anderson, G.K. and Yang, G. (1992). Determination of bicarbonate and total volatile acid concentration in anaerobic digesters using a simple titration. Water Environment Research. 64(1): 53-59. https://doi.org/10.2175/WER.64.1.8

[3] Anthony, A., Ali, M., Muhammad, N. and Karin, G. (2019). A Review of the Chemistry of Anaerobic Digestion: Methods of Accelerating and Optimizing Process Efficiency. Processes. 7(8): 504 https://doi.org/10.3390/pr7080504. 
[4] Buswell, A.M. and Mueller, H.F. (1952). Mechanism of methane fermentation. Industrial \& Engineering Chemistry. 44(3): 550-552. https://doi.org/10.1021/ie50507a033

[5] Callaghan, F.J., Wase, D.A.J., Thayanithy, K. and Forster, C.F. (2002). Continuous co-digestion of cattle slurry with fruit and vegetable wastes and chicken manure. Biomass and bioenergy. 22(1): 71-77. https://doi.org/10.1016/S09619534(01)00057-5

[6] Diaz, L. F., Savage, G M., and Golueke, C. G. (2002). Composting of municipal solid wastes. In Hand book of Solid Wastes Management Integrated solid waste management: engineering principles and management issues. Tchobanoglous, G. and Kreith, F. (Eds.) McGraw-Hill, Inc. DOI: $10.1036 / 0071356231, \quad$ https://sanitarac.pro/wpcontent/uploads/2017/07/Solid-Waste-Management.pdf

[7] Flaga, A. (2005). Sludge Drying, Institute of Heat Engineering and Air Protection, Cracow University of Technology, ul. Warszawska 24, 31-155 Kraków, Poland. https://www.kth.se/polopoly_fs/1.650658.1550158418!/JPS11 p9.pdf

[8] Jansson, A. T., Patinvoh,R.J., Horváth,I.S. and Taherzadeh, M. J. (2019). Dry Anaerobic Digestion of Food and Paper Industry Wastes at Different Solid Contents. Fermentation. 5, 40; doi:10.3390/fermentation5020040, https://doi.org/10.3390/fermentation5020040

[9] Liu, C.F., Yuan, X.Z., Zeng, G.M., Li, W.W. and Li, J.(2008). Prediction of methane yield at optimum $\mathrm{pH}$ for anaerobic digestion of organic fraction of municipal solid waste. Bioresource technology, 99(4): $\quad$ 882-888. https://doi.org/10.1016/j.biortech.2007.01.013

[10] Manilal, V. B. (2012). An improved anaerobic system for household wastes, Patent publn-WO2013140416 A1.

[11] Mao, C.L.; Feng, Y.Z.; Wang, X.J. and Ren, G.X. (2015). Review on research achievements of biogas from anaerobic digestion. Renew. Sust. Energ. Rev. 45: 540-555.

[12] Mir, M. A., Hussain, A., Verma, C . (2016). Design considerations and operational performance of anaerobic digester: A review. Journal of Cogent Engineering. 3: 1181696. https://doi.org/10.1080/23311916.2016.1181696

[13] Mohan, S. and Bindhu, B.K. (2008). Effect of phase separation on anaerobic digestion of kitchen waste. Journal of Environmental Engineering and Science.7(2): 91-103. ISSN 1496-256X, pp. 91-103

[14] Møller, J., Alessio Boldrin, A. and Christensen, T. H. (2009). Anaerobic digestion and digestate use: accounting of greenhouse gases and global warming contribution. Waste Management \& Research. 27: 813-824. https://doi.org/10.1177\%2F0734242X09344876.

[15] Ragazzia, M. Maniscalcoa, M., Torrettab, V., Ferronatob,N., E. C. Radaa, E.C.( 2017). Anaerobic digestion as sustainable source of energy: A dynamic approach for improving the recovery of organic waste. Energy Procedia .119: 602-614. https://www.sciencedirect.com/\#open-access

[16] Scarlat, N., Fahl, F. and Dallemand, J.-F. (2018). Biogas: Developments and perspectives in Europe, Renewable energy. Volume 129, Part A, Pages 457-47. https://doi.org/10.1016/j.renene.2018.03.006

[17] Smis, Jan R. G. and De Baere Luc, A. (1995). Method for the anaerobic decomposition of organic waste, US patent $5,389,258$.

[18] Wellinger, A., Murphy, J. and David Baxter, D. (Eds.) (2013). The Biogas Handbook: Science, Production and Applications, Woodhead Publishing, ISBN:9780857094988

[19] Zhang, R., El-Mashad, H. M., Hartman, K., Wang, F., G. Liu, Choate, C. and Gamble, P. (2007). Characterization of food waste as feedstock for anaerobic digestion, Bioresource Technology. 98: 929-935. doi:10.1016/j.biortech.2006.02.039 